\title{
Historical perspective of drought response in central-southern Italy
}

\author{
Nazzareno Diodato $^{1, *}$, Gianni Bellocchi ${ }^{1,2}$ \\ ${ }^{1}$ Met European Research Observatory, GEWEX-CEOP Network - World Climate Research Programme, via Monte Pino, \\ 82100 Benevento, Italy \\ ${ }^{2}$ Grassland Ecosystem Research Unit, French National Institute of Agricultural Research, Site of Crouël, \\ 234 Avenue du Brézet, 63000 Clermont-Ferrand, France
}

\begin{abstract}
We studied drought records from a large documentary heritage (1581-2007) of central-southern Italy, encompassing the Little Ice Age (LIA), the transitory period (1870-1920) after the LIA, and the recent warming period. Drought conditions were reconstructed via weather indices, and historical written records of the effects on agriculture and living conditions were taken as proxies of drought coding. Wet-dry cycles were analyzed via wavelet power spectrum for localization of climate signals and showed pronounced interannual variation, along with multidecadal oscillations of drought regimes. For the LIA, fluctuations between dry and wet conditions were observed, with less frequency of intermediate states (between the wettest and the driest years) than in recent times. Distinct 11 and 22 yr timeframes that tend to respectively reflect single and double sunspot cycles were identified. The long-term oscillations were intriguingly coupled with large atmospheric pressure pulsations in the central Mediterranean, although the correlation patterns between drought magnitude and large-scale forcing were unevenly distributed.
\end{abstract}

KEY WORDS: Documentary data $\cdot$ Drought $\cdot$ Little Ice Age $\cdot$ Central-southern Italy

\section{INTRODUCTION}

Knowledge of past climate is essential to understanding aspects of climate extremes, such as excessive drought or wet periods, that occur as part of the long-term natural variability of the climate system (Jungclaus 2009). Interannual variability in drought severity, intensity and spatial extension is an important part of the climate signal and can be used to detect potential changes in climate that may have important impacts on both the environment and on society (deMenocal 2001). Although global scale simulations project future increases in drought frequencies in many parts of the world, changes in flood and drought cannot be explained simply by changes in precipitation amounts and intensities (Hirabayashi et al. 2008). Using a process-based biogeochemistry ecosystem model, Xiao et al. (2009) showed that severe extended droughts can affect the terrestrial carbon dynamics. Analyses led by Dai et al. (1998) documented increased areas of the world affected by either drought or excessive wetness. The magnitude and the effect of drought may also be different from region to region. For Hungary, an increasing trend in droughts was shown, with a decrease in wet spells (Szinell et al. 1998). In Turkey, a linear relation was observed between drought intensity and drought magnitude (Sirdaş, Şen 2003). In the whole lowland part of the Elbe basin (Germany), dry spells showed increasing trends for the period 1951-2003 (Krysanova et al. 2008). Multi-century reconstructions for Morocco captured dry conditions after the 1980s, although pluvial events in past times were preceded by generally drier conditions back to 1049 (Esper et al. 2007).

Direct relationships to recent global warming have been inferred from the extreme nature of high temperatures and heat waves accompanying especially 
recent droughts (Luterbacher et al. 2004). In particular, drought in the Mediterranean region was recently shown to precede, and to contribute to, the development of extreme heat in continental Europe (Borga et al. 2007). However, inter-decadal variability in meteorological drought for this region has been identified in only a few climatological and environmental studies (Brewer et al. 2007, Diodato \& Bellocchi 2008, Nicault et al. 2008). This is because instrumental records are not long enough to document the entire range of natural variability within the climate system, particularly for low frequency (multidecadal to century scale) variability (deMenocal 2001).

In cases where sufficient instrumental data are unavailable, the reconstruction of past drought occurrences may be made using data reported in primary sources. In historical documents, diaries, annals, letters, and newspapers or other written reports, extreme events are usually mentioned and recorded almost continuously. According to Mann et al. (2000), sparse documentary and proxy data can also provide reliable climate information back in time. The recent availability of regional sources of annual or seasonal resolution proxy data, combined with the few long instrumental and historical climate records available during the past few centuries, make it possible to reconstruct annual and seasonal temporal patterns of hydrological data variation, some centuries back in time. Increasingly, studies based on the assimilation and analysis of high resolution climate data from global networks have proven to be useful for assessing global or hemispheric patterns of climate in past centuries (Crowley \& Lowery 2000). The crosschecking of reconstructions from different sources of proxy data (e.g. documentary evidence and tree-rings) is also an important method to improve our knowledge about past climates at local and regional scales (Linderholm \& Molin 2005). Natural archives that record seasonal or annual climate conditions, such as ice cores, tree-ring measurements, laminated sediments, and corals, can be proficiently combined with the scant available historical documentary or instrumental evidence from prior centuries. For assessing yearby-year or even decade-by-decade chronology of climate variation, however, high resolution proxy climate indicators remain essential. Documentary data series are expected to correlate with temperature, the overall explained variance being $~ 70 \%$ (Leijonhufvud et al. 2008, Dobrovolný et al. 2010). Correlation between tree-ring proxies and temperature data was found to only explain $\sim 50 \%$ of the variance (Helama et al. 2009, Tan et al. 2009). Indeed, regional climate reconstructions based on tree-rings are com- plicated by the fact that trees respond to different climate parameters in different parts of a region (Brewer et al. 2007).

In general, there are obvious similarities among the reconstructed drought time series at different sites for a given region, particularly on long timescales, with the similarities diminishing only with large increasing separation between locations. In the European regions, the pattern of weather types and drought events was variable over the so-called Little Ice Age (LIA, 14001850; Pfister 2005) and during the 20th century (LloydHughes 2002). During the LIA, weather was not uniformly cold and dry. However, it was accompanied by more frequent and extreme cold events than at present, including several important periods of drought (White 2006).

Italy, which is centrally located in the Mediterranean basin, is the focus of this paper. Changing patterns of drought and hydrological extremes are apparent between the north and the centre-south of the country where opposed atmospheric circulation is often observed (Diodato 2007). In this study, drought analysis was limited to peninsular central-southern Italy and Sicily (hereafter referred to as the Mediterranean Sub-regional Area, MSA), which is largely affected by alternate perturbations and invasions of the sub-tropical anticyclone (Brunetti et al. 2006). The research aimed at understanding, in the long term, the frequency of drought in the MSA in order to characterize the occurrence of dry periods and relate them to climate forcing. The study area, documentary data and analysis techniques are presented in Section 2. In Section 3, long-term dynamics are investigated with the support of the wavelet power spectrum method after an exploratory analysis of the reconstructed series of drought data. In Section 4, remarks are made concerning the bearing of the findings on a wider interpretation of drought phenomena in the context of planetary and regional forcing agents.

\section{METHODOLOGY}

\subsection{Documentary proxies and data compilation}

The study is based on a set of reconstructed drought events assembled from different locations within peninsular central-southern Italy and Sicily (MSA, Fig. 1). The study area partly or entirely encompasses the administrative regions of Apulia, Basilicata, Calabria, Campania, Latium, Molise and Sicily $\left(\sim 90000 \mathrm{~km}^{2}\right)$, and is roughly approximated by the 


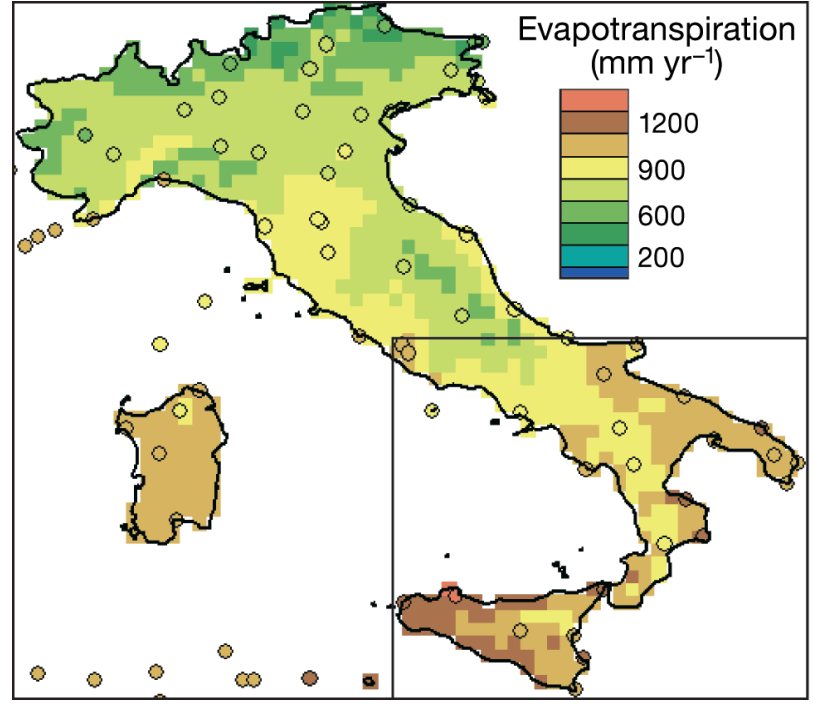

Fig. 1. Annual reference evapotranspiration estimates using the Penman-Monteith equation for Italy (as arranged using LocClim FAO software, www.fao.org/NR/climpag/pub/en3_ 051002_en.asp). Square box: Mediterranean Sub-regional Area (MSA) investigated in this study, where drought conditions are more severe than in northern Italy

box in Fig. 1 (lower left corner: $36.8^{\circ} \mathrm{N}, 13.6^{\circ} \mathrm{E}$; upper right corner: $41.9^{\circ} \mathrm{N}, 18.8^{\circ} \mathrm{E}$ ).

A dataset of drought events was compiled for this area up to the 19th century from various kinds of documents (Fig. 2), based on the methodology outlined by Camuffo \& Enzi (1991) for climate reconstruction from historical sources. The sources used in this study included archival records from the 13th to the 19th centuries, chronicles over the time span 1500

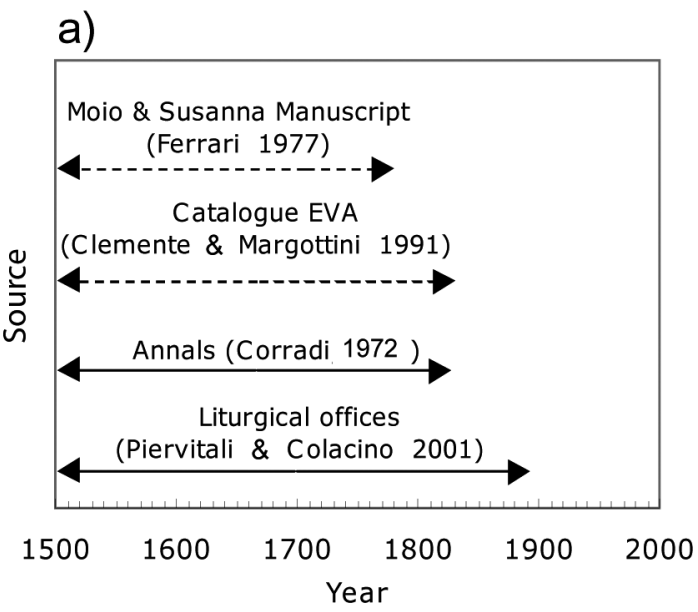

1760 (Ferrari 1977), century-old annals (Corradi 1972), liturgical offices (Piervitali \& Colacino 2001), and one data bank (Catalogue EVA - Environmental Events of the ENEA - Italian National Agency for New Technologies, Energy and the Environment; Clemente \& Margottini 1991).

In particular, the annals of Corradi (1972) report on the environmental and climatological extremes that occurred in Italy from 5 to $1850 \mathrm{AD}$. The chronicles of Giovanni Battista Moio and Gregorio Susanna (Ferrari 1977) report on climate extremes and famines for the Calabrian region from 1710 to 1769 , and include continuous weather information for Catanzaro $\left(38^{\circ} 54^{\prime} \mathrm{N}, 16^{\circ} 36^{\prime} \mathrm{E}\right)$ from the 15th to the 18th centuries. These 2 pre-instrumental sources were systematically used to evaluate occurrence, duration and geographical location of droughts. The Catalogue EVA (Clemente \& Margottini 1991) and documentation of liturgical offices and archival records were also referred to and used when necessary. Breaks in the chronological records (Fig. 2a) are evidence of some typical discontinuities of documented events and show the required compensation for the synoptic analysis of different sources. These sources report records of meteorological and environmental observations for hundreds of sites, with an imprecise description, depending on the area and the period, that makes it difficult to establish the exact location and time of the event. The manuscript texts usually focus on the consequences of extreme meteorological phenomena. The damages caused are described in detail and the institutions involved often provided an estimate of the economic cost of any repairs or rebuilding work necessary. The impacts on the envi-

Fig. 2. (a) Chronological time span of historical sources used to collect drought events over the MSA (solid and dashed arrows: continuous and discontinuous temporal data sources, respectively). (b) Drought reconstruction for a selected number of years (monthly values of the drought index, DI, are reported together with the yearly sum, DIsum) 
ronment and the population depended on various factors and it was not always easy to compare the severity of the climatic conditions, unless they were associated with specific effects. By 1590, harvests were rarely above the subsistence level in some regions, landholdings were fragmented, and peasants were putting pastures and woodlands under the plough. Some local price indices also revealed a particular increase in the years of prolonged drought shown for the 1590s. These years correspond to one of the coldest segments of the LIA (Fagan 2000), marked by vigorous glacier advance in the Alps, consistent with low summer and spring temperatures (Steiner et al. 2008) and generally drier conditions than those normally prevailing in Europe (Casty et al. 2005).

The breakdown of deaths by season and age indicated that disease frequently killed more people than starvation in European LIA mortality crises. Disease could strike in one or more of 3 ways: (a) opportunistic infections bred by starvation, (b) infections bred by poor sanitary and living conditions among famine refugees, and (c) diseases bred by the crowding of famine refugees in population centres (Livvi-Bacci 1990).

As reported by Xoplaki et al. (2001), a dry period during the growth stage or immediately after the sowing of grains in the Mediterranean basin could seriously damage the harvest. This damage was apparent a few months later and might, if drought was long and continuous (e.g. in the year 1760), have affected the harvest and compromised the agronomic and hydrological system, as Gregorio Susanna affirmed in his diary for 1760-1761 (Diodato 2007, p. 420):

Today, Wednesday 31st December the year 1760 is finishing, thank goodness. Food supplies have been very low because of the great drought that never seems to stop, decimating all fruits, with grapes also destined to perish, and very little must and wheat and oil (...). Drought has occurred because there has been no rain up to late December, the countryside is arid and bare of grass, and almost all the cattle are dead. Starvation threatens; much prayer is in order. God have mercy on us! Amen ...

Famines and disastrous years that occurred in specific regions of Italy were also caused by unexpected climatic fluctuations, as noted from the chronicles of Giuseppe Loffredo (De Rienzo 1924, p. 6-7) :

This century XVIII had a memorable and shocking year, for the fatal consequences caused by the scarcity of food and very poor harvest (...). At the beginning of this year, August 1763, drought and hail fell upon the Kingdom of Naples, causing a very poor harvest, with starvation beginning in December (...)
Fluctuations were also observed in the year 1788, as recorded by Canon Giuseppe Maria Giovene (1753-1837) for Apulia in his diary (Corradi 1972, Vol. 2, p. 696-697):

An overall rainy year troubles us with an obstinate and tearful drought; a year that was largely very warm punished us nevertheless with extraordinary cold and frost.

\subsection{Reconstruction and analysis of drought data}

Quantification of the intensity and extent of meteorological phenomena can be done by means of indices, as shown in historical climatology studies (e.g. Brázdil et al. 2005). In this study, the methodology used to reduce the level of subjectivity of the sources involved estimating the number of drought months in a year via a drought index (DI) and accumulating them for all the years. A drought month was identified as a month with DI $=1$ when there was meteorological drought associated with agricultural drought in at least 2 sites (belonging to distinct administrative regions). We set DI $=0$ otherwise. This concept of drought, which was elaborated following Rodrigo et al. (1998, 1999), considers the reduction in rainfall amounts associated with an impact on the agricultural activities (deficit in the runoff of rivers was not explicitly mentioned). A matrix of the results for the period 1751-1760 is shown in Fig. 2b, incorporating monthly and yearly DI values, and the corresponding sources. Monthly values were not always available, as the number of dry months in a year was occasionally provided without identifying specific months of dry extremes. For instance, in 1599, notary Mario Cappella referred to $4 \mathrm{mo}$ of drought in Cerreto Sannita $\left(41^{\circ} 17^{\prime} \mathrm{N}, 14^{\circ} 33^{\prime} \mathrm{E}\right)$ and Terra di Lavoro (historicalgeographical district, part of the current administrative regions of Campania, Lazio and Molise), but which 4 months, and whether or not they were consecutive, is unknown (Cappella 1599).

Our reconstruction started with the year 1581. Prior to this date, spatial data density was too low for reliable sub-regional reconstruction. Different sources led to specific problems and consequently needed a critical approach to introduce rigour into the estimates, e.g. making use of historical and statistical criteria to evaluate the reliability and completeness of documentary records series (Diodato 1999). Our results were validated by comparison following Pfister et al. (2008) whenever multiple sources were available. The reconstruction was built on documen- 
tary information from contemporary sources. Otherwise, at least 2 concordant sources having reliable estimates from data obtained from non-coeval sources were considered. For methodological issues, the readers may also refer to other papers where the general principles of reconstruction from the same body of documentary data were described (Diodato 2007 for precipitation, Diodato et al. 2008 for erosive rainfall, and Diodato et al. 2010 for air temperature modelling).

A drought year was identified when at least 3 contiguous months were arid (DI = 1). A drought weighted index sum (DWIS), synthesizing the drought indices used in this work, was calculated for each year in a $31 \mathrm{yr}$ moving window of binary values by setting the following thresholds (DWI): 0 for absence of drought; 1 for $3 \leq$ drought duration $\leq 5 \mathrm{mo}$; and 2 for drought duration $>5$ mo in each year. DWIS may range from 0 (absence of drought over 31 consecutive years) to 62 (long drought on each of 31 consecutive years). The window of $31 \mathrm{yr}$ corresponds to the need of a centred moving window of $30 \mathrm{yr}$ length (climate normal).

In general, the time series obtained from proxybased reconstructions have to be verified based on instrumental measurements including associated uncertainties (e.g. Dobrovolný et al. 2010). For drought, however, evidence is only given by documentation of climatic stress (e.g. Barriendos 2005). In this case, comparison with other appropriate reconstructions is useful to reveal the extent to which the new reconstruction adds new information and illuminates properties of both the new and existing reconstructions. In order to verify the reliability of the chronological estimations of drought, we thus referred to a drought reconstruction with the aridity index elaborated by De Martonne (1923): $P /(T+10)$, where $P=$ annual precipitation in $\mathrm{mm}_{i}$ and $T=$ mean annual air temperature in ${ }^{\circ} \mathrm{C}$. Increased aridity is assumed when the index diminishes. The aridity index was calculated on reconstructed datasets $\left(0.5^{\circ}\right.$ spatial resolution) of seasonally resolved land air temperature (Luterbacher et al. 2004) and precipitation (Pauling et al. 2006) from a compilation of proxy and instrumental data that dates back to 1500 .

For the reconstructed records (summing up shortterm and prolonged droughts), the dominant timescales in drought occurrences were examined using the wavelet power spectrum (WPS) method. Wavelet power-spectrum graphs were produced by using the Morlet transform of the wavelet, which consists of a plane wave modified by a Gaussian envelope (Torrence \& Compo 1998).

\section{RESULTS}

\subsection{Verification of chronological estimations}

The comparison between DWIS and De Martonne's aridity index using an independent dataset (15811980) can be appreciated in Fig. 3 (where the data were smoothed using a running window of $31 \mathrm{yr}$ ).

The maximum value of DWSI (17) was observed in 1931, 1932 and 1934. Other extreme values (DWSI = 14 to 16) were observed, e.g. towards the end of the 18 th century $(\sim 1790)$. In general, the 2 indices are similar with respect to fluctuations, maxima and minima (Fig. 3a).

We tried to discern what may have been the causes of the discrepancy observed across the 18th century by inspecting the centres of action associated with the European circulation over 2 relatively homogeneous periods of equal length: 1730-1770 and 18001840. Some discrepancies observed before the 18th century were not assessed because the climate reconstructions used to calculate the aridity index in the earlier periods were insufficiently accurate for a detailed investigation (mainly because of the paucity of the data, e.g. Goosse et al. 2010). The year 1840 was taken as the upper limit of the range examined because it marked a discontinuity: there was close proximity between the 2 indices up to 1840 before they mutually de-phased until 1860 (Fig. 3a). Due to the limited time span, this discrepancy was left unexplained. During the ascendant phase of the shift (1730-1770, Fig. 3b), cold anticyclones pushing from the north characterized drought over the Mediterranean area. Fig. 3b reflects an overlap between the positive phases of both the North Atlantic Oscillation (NAO) index and the Scandinavian pattern, which makes the Mediterranean descending flows from the north-northeast more probable, bringing dry conditions associated with below-normal temperatures. The positive phase of the Scandinavian pattern, which was characterized by a strong anomaly centred over the Scandinavian Peninsula, determined a decrease in temperature over the central-western Mediterranean. The concurrent impact of a positive NAO anomaly was a modest decrease in the surface temperature over the south eastern Mediterranean, together with a decrease in precipitation over the Mediterranean (cold drought). In contrast, in the descendant phase of the shift (1800-1840), sub-tropical anticyclones were prevailing (Fig. 3c). Under a negative phase of the NAO index, the European continent was affected by zonal fluxes, with dry and cold 


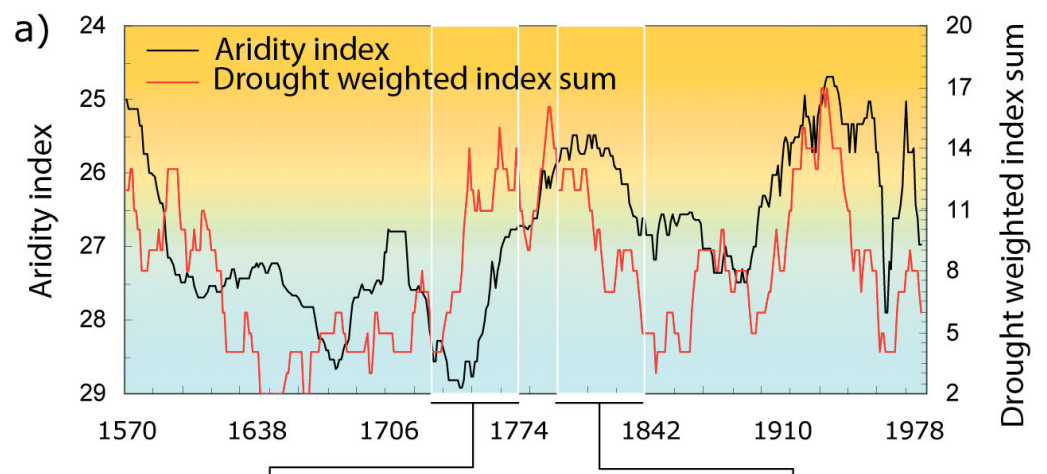

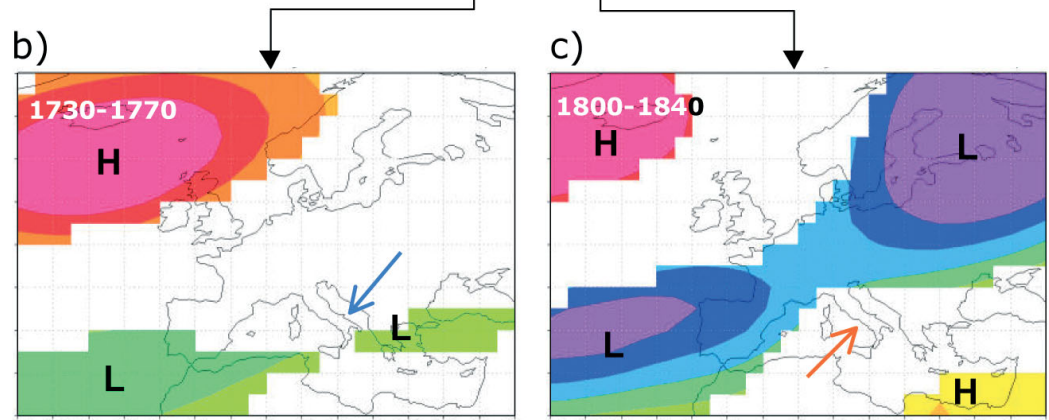

$500 \mathrm{hPa}$ geopotential height anomalies $(\mathrm{m})$

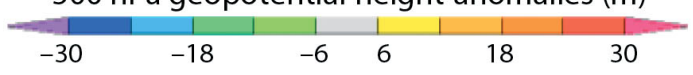

Fig. 3. Comparison of aridity indices and their association with geopotential height. (a) Comparison between De Martonne's aridity index (31 yr running median, black line) and reconstructed drought (31 yr running sum, red line) over southern Italy, 1581-1980. $500 \mathrm{hPa}$ geopotential heights $(\mathrm{p}<0.10)$ of annual mean anomalies (monthly data from Luterbacher et al. 2002) for (b) 17301770 and (c) 1800-1840 are compared to 1850-2000 long-term averages (maps supplied by the web-GIS Climate Explorer, courtesy of the Royal Netherlands Meteorological Institute; van Oldenborgh et al. 2009). H, L: high and low pressure, respectively

conditions in northern Europe and wet conditions (with high temperatures) in southern Europe. More details on the relationship between atmospheric circulation and weather conditions (temperature and precipitation) in Europe are available in Ciccarelli et al. (2008), and Ramos et al. (2010). Only the aridity

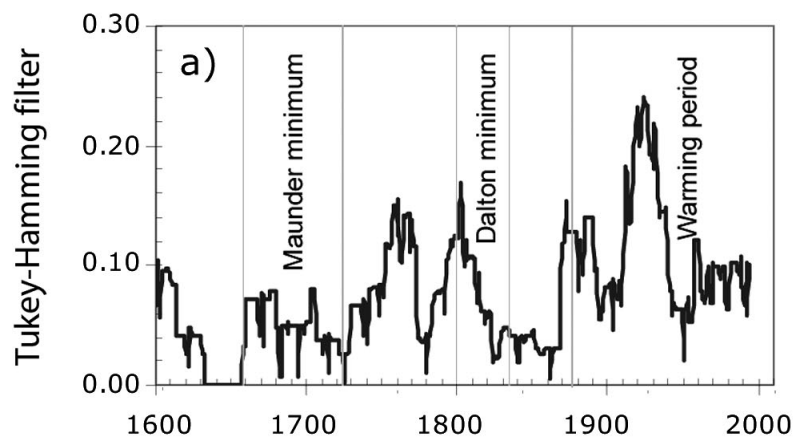

index (plotted in inverted scale in Fig. 3a) that explicitly includes the effects of both temperature and rainfall reflects these alternating conditions, with lower values of aridity in the ascending phase (cold interval) and higher values in the descending one (warm period).

\subsection{Exploratory data analysis}

An exploratory analysis was made to identify time patterns in the reconstructed series of drought indices. A simplified filtering, i.e. TukeyHamming (TH) windowing (Blackman \& Tukey 1958), was used with a given bandwidth to accommodate interdecadal variability detection $(23 \mathrm{yr}$ centred moving average, reflecting historical sunspot observations; Vaquero 2007) on both short-term ( $\geq 3 \mathrm{mo}$

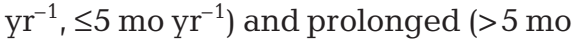
$\mathrm{yr}^{-1}$ ) droughts (Fig. 4). The reconstruction shows the occurrence of important (in both magnitude and intensity) drought events in the last century, although a long-term linear increase versus time is not apparent with prolonged droughts (Fig. 4b). The increasing maxima observed with short drought events (Fig. 4a) confirm the important role played by the recent warming in increased drought conditions (Nicholls \& Alexander 2007). We speculate, however, that the situation depicted in Fig. 4a could have been even more exacerbated than we have been able to show, due to the difficulty in detecting low-

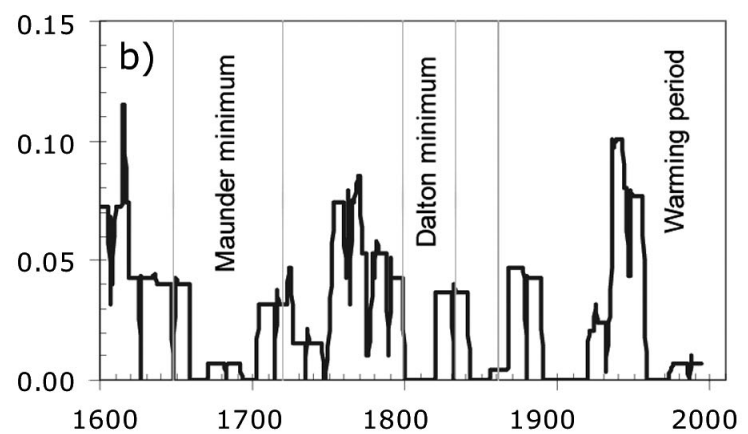

Fig. 4. Long-term variability in drought weight index (DWI) values in the MSA: (a) short droughts, and (b) prolonged droughts, represented by the Tukey-Hamming filter with a 23 yr moving window 
magnitude drought in historical times. This may also explain why maximum values of DWSI (Fig. 3a) were rarely observed before the late 18th century.

The variability of drought observed in Fig. 4b reflects the drought fluctuation dynamics reconstructed by Nicault et al. (2008) for the west Mediterranean, which was characterized by marked dry episodes in the first part of the 17th century similar to those observed at the end of the 20th century. Peaks of drought periods in the early part of the 17 th century and mid-18th century were also recorded for Central Spain by Domínguez-Castro et al. (2008), according to pro-pluvia rogations. It is known that drought variability is often consistent with the assumption of an external global force such as solar force, e.g. Tian et al. (2006). Variations in solar activity seem to be a plausible source of forcing phenomena at high latitudes of both hemispheres, but the physical nature of this cyclicity still remains unclear (e.g. Raspopov et al. 2004). In the area of interest and for the time span investigated, drought maxima and minima were identified in time profiles that tended to reflect periods associated with maximum or minimum solar activity (sunspot cycle). The Maunder minimum (MM) is the name given to the period roughly from 1645-1715, when sunspots became exceedingly rare, as noted by solar observers of the time (Vaquero et al. 2002).

Other historical sunspot minima, including the less marked Dalton minimum (1790-1820), have been detected (Schröder et al. 2004). The Dalton minimum is reflected in a minimum of prolonged droughts (beginning of $1800 \mathrm{~s}$, Fig. 4b), while both the reconstructed short-term and extended droughts tend to overlap around the time of the MM (Fig. 4a,b). Both graphs in Fig. 4 suggest that the present epoch is at the onset of an upcoming local minimum in the longterm solar variability (Bonev et al. 2004). In terms of drought duration, we unexpectedly detected that the past climate that includes the MM interval was characterized by more extremes in terms of months with continued drought (Fig. 5a). In Fig. 5, the horizontal hatched lines assume 9 against 8 mo drought return periods of $\sim 200 \mathrm{yr}$ over 1601-1750 (Fig. 5a) and 1858-2007 (Fig. 5b), respectively. This implies that at this time, climate could have alternated between years accompanied by continuous rain and years with prolonged drought $(\geq 10 \mathrm{mo})$. During the recent phase of warming, this mode of climate variability seems to have softened (Fig. 5b).

\subsection{Temporal and spatial patterns}

A climate signal generally represents the culmination of interactions among physical processes operating on a wide range of spatial and temporal scales. Summing up short-term and prolonged droughts via the DWIS, the dominant timescales in drought occurrences were examined using wavelet power spectrum (WPS) methods (Fig. 6).

In Fig. 6a, extended coloured bands with higher values indicate that high activity (significant drought events, $\mathrm{p}<0.10$ ) occurred overall (although fragmentarily) during roughly the 18th century in the intermediate cycles (relatively high frequency). Fig. 6b confirms the prominent spectral peak of a 22 yr cycle, while the $11 \mathrm{yr}$ cycle is active in more fragmented modes. Such frequency components may be regarded as reflections of cyclical developments of forcing conditions.

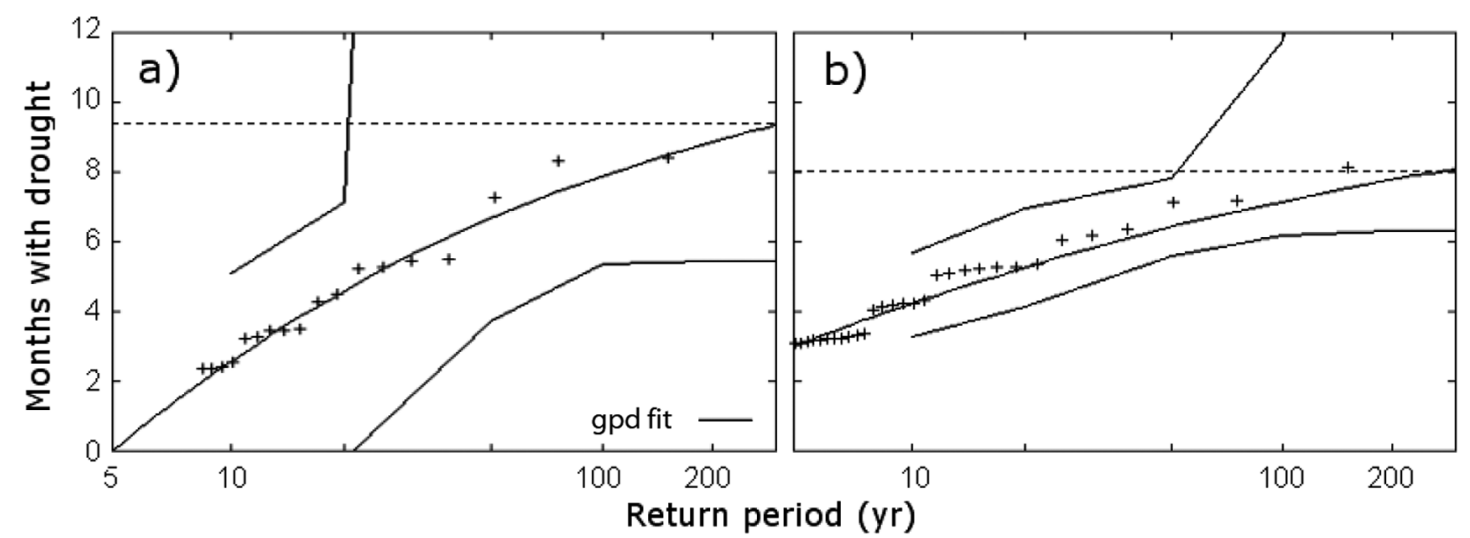

Fig. 5. Gumbel plot (Generalised Pareto Distribution-based) of drought-detrended length (mo) versus return period (log scale) over the MSA: (a) 1601-1750 (cold period), and (b) 1858-2007 (warm period). Horizontal dashed lines assume 9 (a) vs. 8 mo (b) drought return period of $\sim 200 \mathrm{yr}$. The interpolating curve is reported with $95 \%$ CIs for the most uncertain return periods (maps supplied by the web-GIS Climate Explorer, courtesy of the Royal Netherlands Meteorological Institute; van Oldenborgh et al. 2009) 

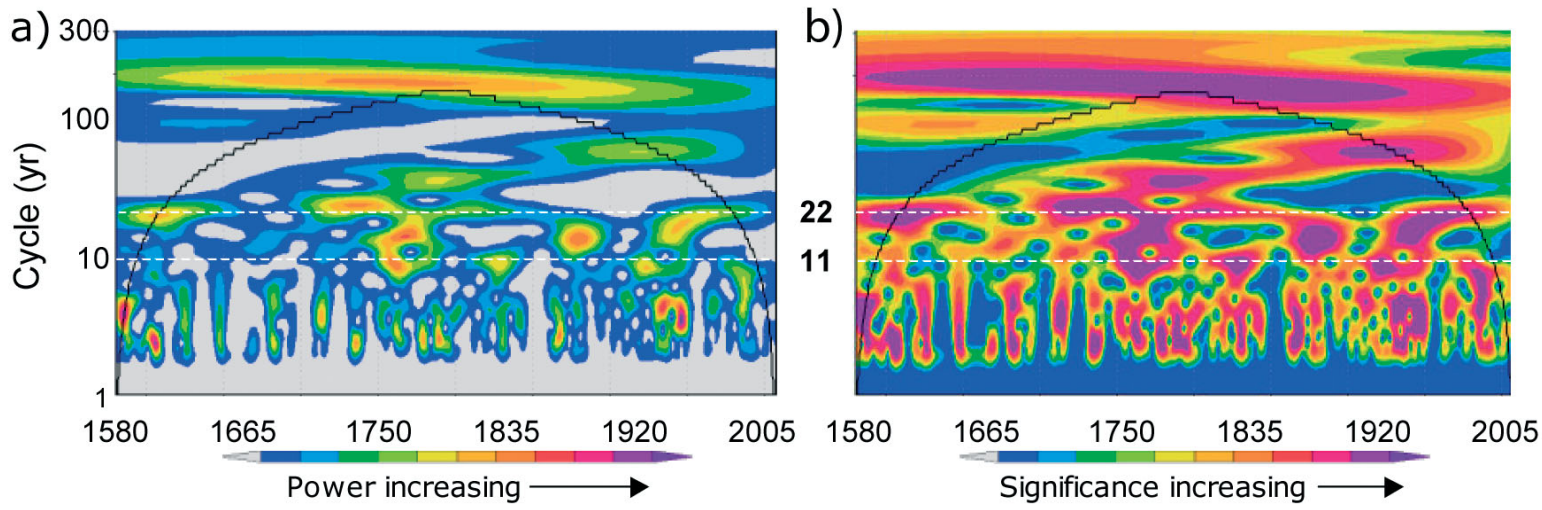

Fig. 6. Wavelet power spectrum (WPS) of the reconstructed drought records in the MSA: (a) WPS of the drought weighted index sum (DWIS) reconstruction, and (b) location of significant edge effects of the local wavelet. Horizontal dashed lines indicate cycles of 22 and $11 \mathrm{yr}$. The graphs were supplied by the web-GIS Climate Explorer, courtesy of the Royal Netherlands Meteorological Institute (van Oldenborgh et al. 2009)

First, solar activity seems to be reflected in the smaller spectral peaks. Sunspot populations are known to quickly rise and slowly fall on an irregular cycle about every 11 yr (Schwabe 1843). A modern understanding of sunspots suggests that a sunspot cycle period of $\sim 22 \mathrm{yr}$ is also apparent (Hale cycle; Vukcevic 2004). Second, sustained dry periods are generally associated with an increase in atmospheric pressure (Brunetti et al. 2002). Statistically significant negative relationships between precipitation anomalies and $500 \mathrm{hPa}$ geopotential height anomalies were also shown, with apparent spatial coherence over Turkey (Türkes et al. 2002). This also agrees with the observational analysis of the northward progression of drought, which may result from the atmospheric transport of anomalous warm and dry air from the southern Mediterranean (Zampieri et al. 2006). However, it is difficult to interpret temporal patterns of regional drought magnitude in terms of broad-scale geopotential forcing, as illustrated in Fig. 7.

Two distinct periods characterized by similar drought conditions - one around the MM (1650$1750)$ and the other during more recent times (18502000) - reveal different geopotential-drought correlation patterns. The heterogeneous spatial correlation pattern in the cold period (1650-1750) was associated with a geopotential-drought correlation limited to the regions Calabria and Sicily (Fig. 7a). In contrast, during the geographically wide-spread, warm-period drought of 1850-2000, the whole central and southern parts of Italy were wrapped in a large significant correlation core (Fig. 7b).

These results should be interpreted with caution because of the lower quality of the data in the earliest period. However, due to the magnitude of the difference between the 2 correlation patterns in Fig. 7 , we assume more varied dynamic mechanisms through

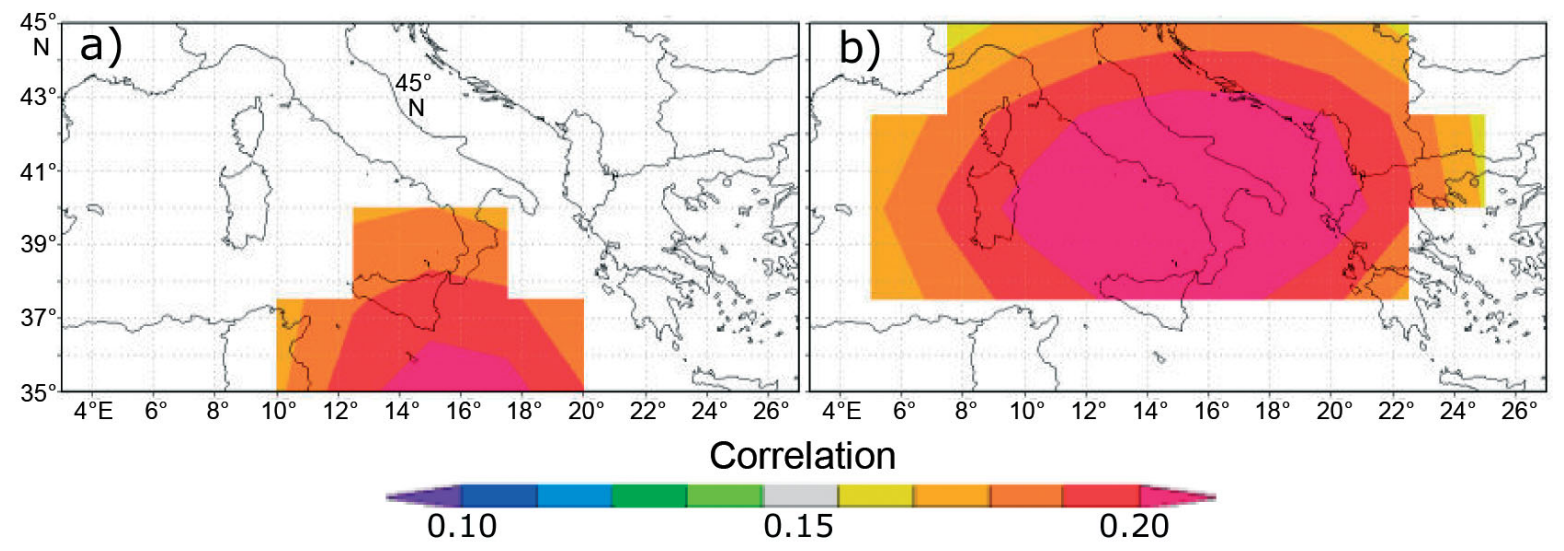

Fig. 7. Spatial correlation ( $\mathrm{p}<0.10$ in coloured bands) between the annual $500 \mathrm{hPa}$ geopotential height and the drought magnitude (consecutive monthly duration) across the central basin of the Mediterranean: (a) 1650-1750 and (b) 1850-2000. Maps were supplied by the web-GIS Climate Explorer, courtesy of the Royal Netherlands Meteorological Institute (van Oldenborgh et al. 2009) based on geopotential data by Schmutz et al. (2001) 
which drought happened in the LIA than in the present warm and dry period. Moreover, a major atmospheric dynamic was also confirmed by the eigenvectors of empirical orthogonal functions of the $500 \mathrm{hPa}$ geopotential height in the LIA. Computed over Europe (data not shown), the eigenvectors exceeded $10 \%$ (in terms of cumulated explained variance) of the values of the modern dynamic patterns. Especially around the MM period, drought occurred primarily with a forced shift towards the low index state of the Arctic Oscillation as solar irradiance and temperature decreased (Shindell et al. 2001). The comparisons performed by Alexander et al. (2004) revealed that the modelled increase in Arctic sea ice reduced the original atmospheric $500 \mathrm{hPa}$ geopotential height anomaly over Europe. In contrast, a shift towards present warmer and drier conditions in the Mediterranean area was observed to be consistent with the general circulation model scenarios enhancing regional subtropical drought over north-western Africa, although different combinations of factors were used, which resulted in distinct regional spatiotemporal drought fingerprints (Touchan et al. 2010).

\section{DISCUSSION AND CONCLUSIONS}

The analysis performed on drought chronologies of the MSA focused ultimately on the variability in the time-domain as obtained mainly from documentary sources. It is difficult to understand to what extent drought conditions can be attributed to various modes of climate variability in the Mediterranean region, and if they can likely be based on responses to general forcing agents. The Mediterranean area is considered to be a delicate environment, in which dry lands are expected to adapt to pressures according to the prevailing climatic situation (Mulligan et al. 2004). Modern drought conditions, accompanied by anthropogenic land mismanagement, can contribute to land degradation already manifested in many parts of the Mediterranean, where intensifying precipitation patterns have been observed, with a higher number of extreme events separated by longer dry periods (Diodato \& Bellocchi 2009). Rainfall variability and its impact on dry land cropping can be alleviated with good management practices that are implemented locally. However, this study provides new evidence of a sequence of drought events imposed in both occurrence and magnitude by larger-scale forces such as anomalies in the atmospheric circulation occurring in the northern hemisphere.
Some correspondence was also observed between droughts and sunspot cycles, which permitted exploration of the possibility of planetary forcing on the local drought variability. Based on transform-driven reconstructed series, periods of low sunspot activity like the MM (roughly spanning from 1645-1715) probably had more effects on drought than local forcing agents. Some similarities are evident in the light of reconstructed historical climatic change in southern Europe, but covering a wide spatial range of patterns. The MM was identified to mark the transition from the dry conditions of the 16th and early 17 th centuries to a later wet period in a study of larger-scale Mediterranean land-area drought fluctuations, based on tree-ring data (Nicault et al. 2008). Compiled drought reconstructions for Morocco (Chbouki et al. 1995) indicate drought-free years from 1760-1780. For central Spain, an increase in the number of droughts emerges for the 1601-1775 period from the reconstruction of drought episodes from rogation ceremonies (Domínguez-Castro et al. 2008). Documentary evidence also reveals that some severe dry periods occurred in southern Portugal during the MM, particularly in 1694 (Alcoforado et al. 2000). According to the reconstruction of Xoplaki et al. (2001) from documentary data assembled from a number of sources, persistent dry seasons affected the meridional Balkans (Greece and the neighbouring countries) over the 17th and 18th centuries. These papers indicate that the 17 th to 18 th century period was characterized by periods in which floods and droughts alternated rapidly and the reconstructions are just a record of a part of such phenomena. Thus, despite the results and temporal resolution, the indications from comparison with existing drought reconstructions must be interpreted cautiously.

Our study stops at 2007. Solar activity has increasingly attracted attention since then due to a new solar quiet registered in recent years (www.spaceweather. com), which is comparable to the Damon minimum of solar irradiance (roughly 1856-1913; Stuiver \& Braziunas 1989). In fact, 2008 was a year of unusually low solar activity, with no sunspots observed for $266 \mathrm{~d}$ (73\%). In 2009, there were $260 \mathrm{~d}$ without sunspots. To find a year with more blank suns, we have to go back to 1913, which had 311 spotless days (85\%). It would be interesting to verify, in the next years, if the expected upswing in solar irradiance (http:// solarscience.msfc.nasa.gov/SunspotCycle.shtml) materializes, how such patterns of solar activity might be reproduced by present-day conditions of drought in the MSA. 
Acknowledgements. We thank R. Touchan of the Laboratory of Tree-Ring Research (University of Arizona, Tucson) for helpful comments while the research was in progress and for reviewing the manuscript; and A. Mancini for English editing.

\section{LITERATURE CITED}

Alcoforado MJ, Nunes MF, Garcia JC, Taborda JP (2000) Temperature and precipitation reconstruction in southern Portugal during the late Maunder Minimum (16751715). Holocene 10:333-340

Alexander MA, Bhatt US, Walsh JE, Timlin MS, Miller JS, Scott JD (2004) The atmospheric response to realistic Arctic sea ice anomalies in an AGCM during winter. J Clim 17:890-904

Barriendos M (2005) Climate and culture in Spain. Religious responses to extreme climatic events in the Hispanic Kingdoms (16th-19th centuries). In: Behringer W, Lehmann H, Pfister C (eds) Cultural consequences of the Little Ice Age. Vandenhoeck \& Ruprecht, Göttingen, p 379-414

Blackman RB, Tukey JW (1958) The measurement of power spectra from the point of view of communication engineering. Dover Publications, New York

> Bonev BP, Penev KM, Sello S (2004) Long-term solar variability and the solar cycle in the 21st century. Astrophys J 605:L81-L84

> Borga M, Boscolo P, Zanon F, Sangati M (2007) Hydrometeorological analysis of the 29 August 2003 flash flood in the Eastern Italian Alps. J Hydrometeorol 8:1049-1067

Brázdil R, Pfister C, Wanner H, von Storch H, Luterbacher J (2005) Historical climatology in Europe - the state of the art. Clim Change 70:363-430

> Brewer S, Alleaume S, Guiot J, Nicault A (2007) Historical droughts in Mediterranean regions during the last 500 years: a data/model approach. Clim Past 3:355-366

Brunetti M, Maugeri M, Nanni T (2002) Atmospheric circulation and precipitation in Italy for the last 50 years. Int $\mathrm{J}$ Climatol 22:1455-1471

Brunetti M, Maugeri M, Monti F, Nanni T (2006) Temperature and precipitation variability in Italy in the last two centuries from homogenised instrumental time. Int J Climatol 26:345-381

Camuffo D, Enzi S (1991) Istruzione per la catalogazione dei dati d'archivio per una ricostruzione di climatologia storica. Boll Geofis 14:133-148

Cappella M (1599) Memoria in margine ad atti notarili, prot. a. 1599 ff. 10 e 134. In: Pescitelli R (ed) Scias Lector... I notai di Cerreto Sannita e loro memorie sec. XIV-XIX, in 'Archivio Storico del Sannio' nr. i 1-2 (estratto), Napoli Edizioni Scientifiche Italiane 1991, p 261 (in Italian)

Casty C, Wanner H, Luterbacher J, Esper J, Böhm R (2005) Temperature and precipitation variability in the European Alps since 1500. Int J Climatol 25:1855-1880

Chbouki N, Stockton CW, Myers D (1995) Spatio-temporal patterns of drought in Morocco. Int J Climatol 15:187-205

Ciccarelli N, von Hardenberg J, Provenzale A, Ronchi C, Vargiu A, Pelosini R (2008) Climate variability in northwestern Italy during the second half of the 20th century. Global Planet Change 63:185-195

Clemente GF, Margottini C (1991) Sistema EVA: una biblioteca di dischi ottici per le catastrofi naturali del passato. Prometeo (Milan) 9:22-29
Corradi A (1972) Annali delle epidemie occorse in Italia dalle prime memorie fino al 1850. Reprint by Arnaldo Forni, Bologna

Crowley TJ, Lowery TS (2000) How warm was the Medieval Warm Period? A comment on 'Man-made versus natural climate change'. Ambio 39:51-54

> Dai A, Trenberth KE, Karl T (1998) Global variations in droughts and wet spells: 1900-1995. Geophys Res Lett 25:3367-3370

De Martonne E (1923) Aridité et indices d'aridité. Académie des Sciences. CR (East Lansing, Mich) 182:1935-1938

> deMenocal PB (2001) Cultural responses to climate change during the late Holocene. Science 292:667-673

De Rienzo A (1924) La carestia e l'epidemia del 1764 in Benevento. Atti della Società Storica del Sannio 2:6-7 (in Italian)

Diodato N (1999) Ricostruzione storica di eventi naturali estremi a carattere idrometeorologico nel Sannio Beneventano dal Medioevo al 1988. Boll Geofis 22:5-39

> Diodato N (2007) Climatic fluctuations in Southern Italy since the 17th century: reconstruction with precipitation records at Benevento. Clim Change 80:411-431

> Diodato N, Bellocchi G (2008) Drought stress patterns in Italy using agro-climatic indicators. Clim Res 36:53-63

Diodato N, Bellocchi G (2009) Environmental implications of erosive rainfall across the Mediterranean. In: Halley GT, Fridian YT (eds) Environmental impact assessments. NOVA Publishers, New York, p 75-101

> Diodato N, Ceccarelli M, Bellocchi G (2008) Decadal and century-long changes in the reconstruction of erosive rainfall anomalies in a Mediterranean fluvial basin. Earth Surf Process Landf 33:2078-2093

> Diodato N, Bellocchi G, Bertolin C, Camuffo D (2010) Multiscale regression model to infer historical temperatures in a central Mediterranean sub-regional area. Clim Past Discuss 6:2625-2649

Dobrovolný P, Moberg A, Brázdil R, Pfister C and others (2010) Monthly, seasonal and annual temperature reconstructions for Central Europe derived from documentary evidence and instrumental records since AD 1500. Clim Change 101:69-107

Domínguez-Castro F, Santisteban JI, Barriendos M, Mediavilla R (2008) Reconstruction of drought episodes for central Spain from rogation ceremonies recorded at the Toledo Cathedral from 1506 to 1900: a methodological approach. Global Planet Change 63:230-242

Esper J, Frank D, Büntgen U, Verstege A, Luterbacher J, Xoplaki E (2007) Long-term drought severity variations in Morocco. Geophys Res Lett 34:L17702 doi:10.1029/ 2007GL030844

Fagan B (2000) The Little Ice Age: how climate made history, 1300-1850. Basic Books, New York

Ferrari U (1977) Giovan Battista Moio, Gregorio Susanna: Diario di quanto successe in Catanzaro dal 1710 al 1769. Effe Emme, Chiaravalle

> Goosse H, Crespin E, de Morney A, Mann ME, Renssen H, Timmermann A (2010) Reconstructing surface temperature changes over the past 600 years using climate model simulations with data assimilation. J Geophys Res 115:D09108 doi:10.1029/2009JD012737

> Helama S, Makarenko NG, Karimova LM, Kruglun OA and others (2009) Dendroclimatic transfer functions revisited: Little Ice Age and Medieval Warm Period summer temperatures reconstructed using artificial neural networks and linear algorithms. Ann Geophys 27:1097-1111 
Hirabayashi Y, Kanae S, Emori S, Oki T, Kimoto M (2008) Global projections of changing risks of floods and droughts in a changing climate. Hydrol Sci J 53:754-772

Jungclaus JH (2009) Palaeoclimate: lessons from the past millennium. Nat Geosci 2:468-470

Krysanova V, Vetter T, Hattermann F (2008) Detection of change in drought frequency in the Elbe basin: comparison of three methods. Hydrol Sci J 53:519-537

Leijonhufvud L, Wilson R, Moberg A (2008) Documentary data provide evidence of Stockholm average winter to spring temperatures in the eighteenth and nineteenth centuries. Holocene 18:333-343

Linderholm HW, Molin T (2005) Early nineteenth century drought in east central Sweden inferred from dendrochronological and historical archives. Clim Res 29: $63-72$

Livvi-Bacci M (1990) Population and nutrition: an essay on European demographic history. Cambridge University Press, Cambridge

Lloyd-Hughes B (2002) The long-range predictability of European drought. PhD thesis, University College of London

Luterbacher J, Xoplaki E, Rickli R, Gyalistras D, Schmutz C, Wanner H (2002) Reconstruction of sea level pressure fields over the eastern North Atlantic and Europe back to 1500. Clim Dyn 18:545-561

> Luterbacher J, Dietrich D, Xoplaki E, Grosjean M, Wanner $H$ (2004) European seasonal and annual temperature variability, trends, and extremes since 1500. Science 303: 1499-1503

Mann ME, Gille E, Bradley RS, Hughes MK, Overpeck J, Keimig FT, Gross W (2000) Global temperature patterns in past centuries: an interactive presentation. Earth Interact 4:1-29

Mulligan M, Burke SM, Concepcion M (2004) Climate change, land-use change and the 'desertification' of Mediterranean Europe. In: Mazzoleni S, di Pasquale G, Mulligan M, di Martino P, Rego F (eds) Recent dynamics of the Mediterranean vegetation and landscape. Wiley, London, p 259-279

> Nicault A, Alleaume S, Brewer S, Carrer M, Nola P, Guiot $\mathrm{J}$ (2008) Mediterranean drought fluctuation during the last 500 years based on tree-ring data. Clim Dyn 31: $227-245$

> Nicholls N, Alexander L (2007) Has the climate become more variable or extreme? Progress 1992-2006. Prog Phys Geogr 31:77-87

Pauling A, Luterbacher J, Casty C, Wanner H (2006) Five hundred years of gridded high-resolution precipitation reconstructions over Europe and the connection to largescale circulation. Clim Dyn 26:387-405

Pfister C (2005) Weeping in the snow: the second period of Little Ice Age-type impacts, 1570-1630. In: Behringer W, Lehmann $\mathrm{H}$, Pfister C (eds) Cultural consequences of the Little Ice Age. Vandenhoeck \& Ruprecht, Göttingen, p 31-86

Pfister C, Luterbacher J, Wanner H, Wheeler D and others (2008) Documentary evidence as climate proxies. Proxyspecific white paper produced from the PAGES/CLIVAR workshop, Trieste, 2008. PAGES (Past Global Changes), Bern. Available at www.ncdc.noaa.gov/paleo/reports/ trieste2008/documentary.pdf

> Piervitali E, Colacino M (2001) Evidence of drought in Western Sicily during the period 1565-1915 from liturgical offices. Clim Change 49:225-238
Ramos AM, Lorenzo MN, Gimeno L (2010) Compatibility between modes of low-frequency variability and circulation types: a case study of the northwest Iberian Peninsula. J Geophys Res 115:D02113 doi:10.1029/2009 JD012194

Raspopov OM, Dergachev VA, Kolström T (2004) Periodicity of climate conditions and solar variability derived from dendrochronological and other palaeoclimatic data in high latitudes. Palaeogeogr Palaeoclimatol Palaeoecol 209:127-139

Rodrigo FS, Esteban-Parra MJ, Castro-Diez Y (1998) On the use of the Jesuit private correspondence records in climate reconstructions: a case study from Castille (Spain) for 1634-1648 A.D. Clim Change 40:625-645

> Rodrigo FS, Esteban-Parra MJ, Pozo-Vazquez D, CastroDiez Y (1999) A 500-year precipitation record in Southern Spain. Int J Climatol 19:1233-1253

Schmutz C, Gyalistras D, Luterbacher J, Wanner H (2001) Reconstruction of monthly 700, 500 and $300 \mathrm{hPa}$ geopotential height fields in the European and Eastern North Atlantic region for the period 1901-1947. Clim Res 18: 181-193

Schröder W, Shefov NN, Treder HJ (2004) Estimation of past solar and upper atmosphere conditions from historical and modern auroral observations. Ann Geophys 22:2273-2276

Schwabe H (1843) Solar observations during 1843. Astron Nachr 20:283-286

Shindell DT, Schmidt GA, Mann ME, Rind D, Waple A (2001) Solar forcing of regional climate change during the Maunder minimum. Science 294:2149-2152

Sirdaş S, Şen Z (2003) Spatio-temporal drought analysis in the Trakya region, Turkey. Hydrol Sci J 48:809-820

Steiner D, Pauling A, Nussbaumer SU, Nesje A, Luterbacher J, Wanner H, Zumbühl HJ (2008) Sensitivity of European glaciers to precipitation and temperature-two case studies. Clim Change 90:413-441

Stuiver M, Braziunas TF (1989) Atmospheric ${ }^{14} \mathrm{C}$ and century-scale solar oscillations. Nature 338:405-408

Szinell CS, Bussay A, Szentimrey T (1998) Drought tendencies in Hungary. Int J Climatol 18:1479-1491

- Tan M, Shao X, Liu J, Cai B (2009) Comparative analysis between a proxy-based climate reconstruction and GCM-based simulation of temperatures over the last millennium in China. J Quaternary Sci 24:547-551

Tian J, Nelson DM, Hu FS (2006) Possible linkages of lateHolocene drought in the North American midcontinent to Pacific Decadal Oscillation and solar activity. Geophys Res Lett 33:L23702 doi:10.1029/20067GL028169

Torrence C, Compo GP (1998) A practical guide to wavelet analysis. Bull Am Meteorol Soc 79:61-78

Touchan R, Anchukaitis KJ, Meko DM, Sabir M, Attalah S, Aloui A (2010) Spatiotemporal drought variability in northwestern Africa over the last nine centuries. Clim Dyn 37:237-252

Türkes M, Sümer UM, Kiliç G (2002) Persistence and periodicity in the precipitation series of Turkey and associations with 500 hPa geopotential heights. Clim Res 21:59-81

> van Oldenborgh GJ, Drijfhout S, van Ulden A, Haarsma R and others (2009) Western Europe is warming much faster than expected. Clim Past 5:1-12

> Vaquero JM (2007) Historical sunspot observations: a review. Adv Space Res 40:929-941

> Vaquero JM, Sánchez-Bajo F, Gallego MC (2002) A measure of the solar rotation during the Maunder minimum. Sol Phys 207:219-222 
Vukcevic MA (2004) Evidence of a multi resonant system within solar periodic activity. arXiv:astro-ph/0401107v2 White SA (2006) Climate change and crisis in Ottoman Turkey and the Balkans, 1590-1710. In: Ünal Y, Kahya C, Demirhan Bari D (eds) Proc Int Conf Climate Change and the Middle East: past, present and future. Department of Meteorological Engineering, Istanbul Technical University, p 391-430

Xiao J, Zhuang Q, Liang E, McGuire AD and others (2009) Twentieth-century droughts and their impacts on terres-

Editorial responsibility: Filippo Giorgi,

Trieste, Italy trial carbon cycling in China. Earth Interact 13:1-31

Xoplaki E, Maheras P, Luterbacher J (2001) Variability of climate in meridional Balkans during the periods 16751715 and 1780-1830 and its impact on human life. Clim Change 48:581-615

Zampieri M, Vautard R, Yiou P, D'Andrea F and others (2006) Progresses in understanding summertime European heat and drought waves (Abstract). 6th Annu Meet European Meteorol Soc, available at http://adsabs. harvard.edu/abs/2006AGUFM.A41B0032Zt

Submitted: January 10, 2011; Accepted: June 6, 2011 Proofs received from author(s): September 18, 2011 